\title{
@OPENACCESS LUMBAR STENOSIS IN SYMPTOMATIC BACKACHE check for udatates PATIENTS OF MORE THAN 50 YEARS AGE
}

\author{
Abdul Samad Panizai ${ }^{1,2}$, Aurangzeb Kalhoro ${ }^{\aleph 1,3}$, Sher Hassan ${ }^{1,2}$, Farrukh Javed ${ }^{1}$, Lal Rehman ${ }^{1}$
}

\begin{abstract}
${ }^{1}$ Department of Nuerosurgery, Jinnah Postgraduate Medical Centre, Karachi-Pakistan

2 Department of Nuerosurgery, Sandeman Provincial Hospital, Quetta-Pakistan. 3 Department of Nuerosurgery, Jinnah Medical \& Dental College, KarachiPakistan.
\end{abstract}

Address for correspondence: Aurangzeb Kalhoro Department of Nuerosurgery, Jinnah Medical \& Dental College, KarachiPakistan.

E-mail:

aurangzeb_k1@yahoo.com

Date Received:

July, $22^{\text {nd }} 2020$

Date Revised:

September, $2^{\text {nd }} 2021$

Date Accepted:

September, $5^{\text {th }} 2021$

This article may be cited as Panizai AS, Kalhoro A, Hassan S, Javed F, Rehman L,. Lumbar stenosis in symptomatic backache patients of more than 50 years age. J Postgrad Med Inst 2021;35(2):114-8. https://doi.org/10.54079/ jpmi.35.2.2749.

\section{ABSTRACT}

Objective: To determine the frequency of Lumbar Stenosis in symptomatic backache patients of more than 50 years age.

Methodology: This descriptive cross sectional study was conducted in Department of Neurosurgery, Jinnah Postgraduate Medical Centre, Karachi, on 169 patients having symptoms from Feb 2017 to January 2019. Non-probability consecutive sampling was used to enroll the sample. After following the ethical practices, taking informed written consent, the pre-designed performa was filled along with the complete history and the examination. Magnetic Resonance Imaging (MRI) lumbosacral spine was advised and patients with lumbar spinal stenosis based on their history, MRI and examination were reported by the consultant radiologist.

Results: In total of 169 participants, the mean age was recorded to be $63 \pm 8.40$ years, wherein 67 (39.6\%) females and 102 (60.3\%) were males. The frequency of spinal stenosis diagnosed on imaging in symptomatic patients was recorded to be as 37.3\% ( $n=63)$. A significant relationship was recorded between gender and professions with LSS ( $p$-value $=<0.05$ ), whereas age group and BMI had an insignificant relationship ( $p$-value $=>0.05$ ). Conclusion: The study concluded that $37 \%$ of the participants with any symptoms were diagnosed as LSS. Furthermore, a positive relationship was determined between gender and profession with LSS.

Keywords: Headache; Computed tomography (CT); Lumbar spinal stenosis; Magnetic resonance imaging (MRI).

\section{INTRODUCTION}

The Lumbar Spinal Stenosis (LSS) is a notable clinical state associated with leg pain, numbness, and intermittent claudication, which may or may not be kindred with low back pain (LBP). These patients mostly present when the changes are evident on radiology with decrease space in the neural canal and central canal of the neural foramina. ${ }^{1}$ Lumbar spinal stenosis is a set of symptoms causing back pain and radiation to either one or both legs, that can be exacerbated by long-standing or maintaining a single posture. The narrow canal space diagnosis of lumbar stenosis is supported by Magnetic Resonance Imaging (MRI) or Computed Tomography (CT) of lumbosacral spine. A reasonable proportion of asymptomatic patients above 60 years of age are shown to have substantial narrowing of the lumbar spine. ${ }^{2}$ The overall prevalence and incidence of symptomatic lumbar spinal stenosis are not well documented. A study in Japan shows that Lumbar spinal stenosis was five-fold more common disorder in patients undergoing spinal surgeries. ${ }^{3}$ In the developed countries, the most usual age group in which people undergo spinal surgery is the age group of $>60$ years, the prevalence of moderate (diameter between 10$12 \mathrm{~mm}$ antero-posterior) lumbar spinal stenosis was $47 \%$ and severe (diameter $<10 \mathrm{~mm}$ antero-posterior) lumbar spinal stenosis was $18 \%{ }^{4}$

The accepted course of lumbar spinal stenosis is comparatively stable with neurological deficit and functional disability developing moderately. Most of the patients are treated by a conventional method in all such cases. ${ }^{5}$ Multiple risk factors predispose individuals towards developing LSS, like advancing age, obesity, smoking, previous spinal injury and genetic factors. Treatment ranges from conservative management to surgical fixation in patients depending on the severity of the symptom, a wide range of conservative and surgical modalities can be recommended. ${ }^{6-11}$ Overall stress is based on the significance of cost-effective management than the standard care by a general practitioner. $^{9}$

Overall, in Pakistan, we have insignificant data regarding the prevalence of LSS, even the worldwide survey is cognizance and diverse of the actual line of management of LSS. The study will determine the 
occurrence of Lumbar Stenosis in indicative backache among patients aged more than 50 years. The study will help in developing of the strategies to cut down the morbidity and resource allocation. These statistics of the study may help doctors in promoting cognizance about spinal stenosis.

\section{METHODOLOGY}

This study was conducted at the Neurosurgery Department of Jinnah Postgraduate Medical Centre, Karachi from 1st Feb 2017 to 30th January 2019. A total of 169 patients were enrolled in the study using non-probability consecutive sampling. The inclusion criteria were symptomatic patients of any gender, aged $>50$ years, difficulty in walking with standing, numbness of legs, back pain for more than three months having lumbar spinal stenosis diagnosed on Magnetic Resonance Imaging (MRI) lumbosacral spine. While the exclusion criteria was patients previously operated for spinal surgery, traumatic spine patients, patients with findings of hyperlordosis, kyphosis, scoliosis with vascular claudication, neoplastic pathology or infective process. After informed consent, a comprehensive history and relevant neurological examination was done along with MRI. The MRI was reported as lumbar spinal stenosis after fulfilling the diagnostic criteria duly reported by the consultant radiologist. Neurogenic claudication was defined as pain in lower back, and lower extremities that is elicited by physical activity (walking or extended standing over 30 minutes), Spinal stenosis: Lumbar spinal stenosis diameter < $10 \mathrm{~mm}$ on MRI was taken as spinal stenosis. SPSS v.20.0 was used to extract the data, descriptive and inferential statistics were applied where needed. Stratification was done based on the, gender, age group, occupation, and BMI to report effect modifiers. Chi-square was applied to observe the outcome of variables. P-value $<0.05$ was taken as noteworthy.

\section{RESULTS}

The mean age of the sample was $63 \pm 8.40$ years. Similarly, descriptive statistics for height, weight, BMI and mean duration of illness are elaborated in table 1. Out of 169 cases, $102(60 \%)$ were male, and 67 (39.7\%) were female. The rate of spinal stenosis was significantly high in females as compared to males (39\% female to male $37.7 \% p=0.044)$.

The frequency of diagnosis of spinal stenosis based on Magnetic Resonance Imaging (MRI) was in 37\% (63/169) cases and rate of spinal stenosis significance among different age groups were recorded as $p=0.086$, as shown in Table 2. Regarding professional affiliation, 38(60.31\%) patients were working in the office while 25(39.67\%) were labour workers and didn't show any significant relationship with the spinal stenosis ( $p$-value 0.19 ) as given in table 2 . The frequency of spinal stenosis in patients was also observed according to the BMl and a ( $p$-value 0.962) was recorded, details given in table 2 .

\section{DISCUSSION}

Although Lumbar Spinal Stenosis (LSS) is considered the main reason for pain and disability, there is very much less information regarding the epidemiology of LSS. Numerous cross-sectional study approaches were previously adopted as it defines and describes radiographic LSS prevalence in a small group population.

In our study, we had the patients being symptomatic regarding back pain for more than 3 months, of either gender, who were asked to go through the radiological investigation; while De Villiers and Booysen et al. ${ }^{12}$ stated in their report that around 850 myelograms were reported with contrasting medium (water-soluble). On the other hand, the researcher did not precisely and accurately define the study samples of LSS prevalence but also described the method for diagnosis of Radiographic LSS method. In yet another study by Deer T et al. ${ }^{13}$ the patient initially remained asymptomatic but once they had symptoms of back pain then it was late for the conservative treatment.

Fanuele et a $\left.\right|^{14}$ stated a population prevalence of $13.1 \%$ among 17,744 samples who were examined and treated at multiple spine centers. In our study, the average age of the patients was $63 \pm 8.40$ years. Out of 169 cases, 103(60.94\%) were male, and 66(39.05\%) were female. In similarity, a study reported 104 (55.6\%) males and 87 (44.4\%)" females. ${ }^{4}$ The standard age was

Table 1: Patients Descriptive Statistics N=169

\begin{tabular}{|c|c|c|c|c|c|c|}
\hline \multirow{2}{*}{ Variable } & Mean. & \multirow{2}{*}{ SD. Deviation } & \multicolumn{2}{|c|}{$95 \%$ C. Interval for Mean } & \multirow{2}{*}{ IQR } \\
\cline { 4 - 6 } & & & Lower Bound & Upper Bound & \\
\hline Age in Years & 63.02 & 8.40 & 61.29 & 64.75 & 62 & 15.0 \\
\hline $\begin{array}{c}\text { Symptomatic Duration } \\
\text { (days) }\end{array}$ & 186.14 & 40.7 & 177.76 & 194.55 & 70 & 75.0 \\
\hline Height in c.m & 163.66 & 10.90 & 161.43 & 165.9 & 165. & 70 \\
\hline Weight in k.g & 70.85 & $9 . .01$ & 68.99 & 72.8 & 18.0 \\
\hline B.M.I (kg/m2) & 26.728 & 4.53 & 25.89 & 27.67 & 25.40 & 7.0 \\
\hline
\end{tabular}


Table 2: Imaging Based Diagnosis Of Frequency Of Spinal Stenosis According To Age Groups n=169

\begin{tabular}{|c|c|c|}
\hline \multirow{2}{*}{ Age Groups (Years) } & \multicolumn{2}{|c|}{ Spinal Canal Stenosis } \\
\cline { 2 - 3 } & Yes & No \\
\hline$<60$ Yrs & $28(44.4 \%)$ & $49(46.2 \%)$ \\
\hline 61 to 70 Yrs & $22(34.9 \%)$ & $37(34.9 \%)$ \\
\hline 71 to 80 Yrs & $12(19.6 \%)$ & $20(18.8 \%)$ \\
\hline Sum up & $63(37 \%)$ & $106(62.7 \%)$ \\
\hline
\end{tabular}

Table 3: Frequency of Spinal Stenosis Diagnosed on Imaging in Symptomatic Patients According to Occupation n=169

\begin{tabular}{|c|c|c|}
\hline \multirow{2}{*}{ Profession } & \multicolumn{2}{|c|}{ Spinal Canal Stenosis } \\
\cline { 2 - 3 } & Yes (\%age) & No (\%age) \\
\hline Office job & $38(60.31 \%)$ & $65(61.31 \%)$ \\
\hline Labor & $25(39.67 \%)$ & $41(38.6 \%)$ \\
\hline Sum up & 63 & 106 \\
\hline
\end{tabular}

Table 4: Frequency of Spinal Stenosis Diagnosed on Imaging in Symptomatic Patients According to BMI n=169

\begin{tabular}{|c|c|c|}
\hline \multirow{2}{*}{ B.M.I } & \multicolumn{2}{|c|}{ Spinal canal stenosis } \\
\cline { 2 - 3 } & Yes (\%age) & No (\%age) \\
\hline 18.5 to $25 \mathrm{~kg} / \mathrm{m} 2$ & $33(50.7 \%)$ & $55(52.8 \%)$ \\
\hline 25.1 to $30 \mathrm{~kg} / \mathrm{m} 2$ & $22(33.8 \%)$ & $34(32.67 \%)$ \\
\hline$>30 \mathrm{~kg} / \mathrm{m} 2$ & $10(15.3 \%)$ & $15(14.1 \%)$ \\
\hline Sum up & 65 & 104 \\
\hline
\end{tabular}

$52.6 \pm 10.8$ (age range was 32 to 79 ).

In this study the frequency of spinal stenosis diagnosed on imaging was $37 \%$ (63/169). Literature is diverse for numbers of spinal stenosis, in a study 17 (35.4\%) asymptomatic persons (who had never had LBP, neurogenic claudication or sciatica) went through an MRI and was recorded to be as LSS. Similarly, $21 \%$ positive results were recorded in individuals above sixty years. ${ }^{15}$ Wiesel and colleagues ${ }^{15}$ showed that $50 \%$ asymptomatic individuals over forty years of age got diagnosed with LSS. In another study conducted on 31 asymptomatic persons, 23 percent had Lumbar spine stenosis (11.5 $\mathrm{mm}$ cut-off point). The frequency of conditional LSS in our study is based on symptomatic individuals which are quite similar to the study of Adachi and colleagues. ${ }^{16}$

This study reveals a high rate of spinal stenosis in females as compared to males $(39 \%, p=0.044)$. In a study by Machado and colleagues ${ }^{17}$ statistics of spinal stenosis surgery in Japan were reported and insignificant statistically relationship was observed among genders. Similarly in a study conducted on 2751 admissions no statistical gender distinction was extracted among patients admitted at William Beaumont Hospital, Royal Oak. ${ }^{18}$ In a study, during the time of service, Verbiest calculated the mid-sagittal diameter of the lumbar canal and introduced two primary forms of stenosis. ${ }^{19}$ Total stenosis, $10 \mathrm{~mm}$ or less in diameter, and relative stenosis, 10 to $12 \mathrm{~mm}$ in diameters, while based on CT scan analysis. ${ }^{20}$

Ulrich and colleagues ${ }^{21}$ proposed that, through the simple axial CT, they can measure the spinal canal anteroposterior that is difficult to be dropped less than $11.5 \mathrm{~mm}$; whereas, on the other hand, Lee and colleagues ${ }^{22}$ stated in another CT study, that "in a typical spine, the sagittal diameter of the lumbar spinal canal is rarely less than $10 \mathrm{~mm}$.

Schonstrom and associates ${ }^{23}$ recom- mended a more accurate diagnostic scale, wherein $<76$ millimeters was taken extremely stenotic, 76 to100 millimeter mildly stenotic and $>100$ millimeters at the narrowest point as normal for the cross-sectional region of the dural sac and distinct cross-sectional regions. Diameter at the sagittal section of $>$ ten millimeters was defined as standard, 8 to 10 millimeter was defined as moderately stenotic, and $<8 \mathrm{~mm}$ as severely stenotic, this shows the sagittal and transverse diameters of the Dural sac having high correlation $(r=0.75) .{ }^{23}$ Jarvik and colleagues ${ }^{24}$ also calculated (gestalt measurement) that severe Lumbar stenosis is less common among non-LBP people. However, Magnetic Resonance Imaging (MRI) in the lumbosacral spine is the imaging modality of choice for the current study, and CT lumbar spine was a second-line alternative for the diagnostic evaluation.

The limitations of the study were that the postoperative images were not done in all patients and the diagnosis was based on 
clinical signs and symptoms. Follow up was limited and the role of physiotherapy was not assessed in pre and post-operative patients. We recommend conducting more such trials in other centers and then a meta-analysis was done to dig out its effects for further elaboration as our study was a single center limited sample trial.

\section{CONCLUSION}

The study concluded that $37 \%$ of the participants with any symptoms were diagnosed as LSS. Furthermore, a positive relationship was determined between gender and profession with LSS.

\section{REFERENCES}

1. Ohtori S, Sekiguchi M, Yonemoto K, Kakuma T, Takahashi K, Konno S. Awareness and use of diagnostic tools for lumbar spinal stenosis in Japan. J Orthop Sci. 2014; 19(3):412-7.

2. Kuittinen P, Sipola P, Saari T, Aalto TJ, Sinikallio S, Savolainen $S$, Kröger $H$, Turunen V, Leinonen V, Airaksinen 0. Visually assessed severity of lumbar spinal canal stenosis is paradoxically associated with leg pain and objective walking ability. BMC musculoskeletal disord. 2014; 15(1):348.

3. Aizawa T, Kokubun S, Ozawa H, Kusakabe T, Tanaka Y, Hoshikawa T, et al. Increasing incidence of degenerative spinal diseases in Japan during 25 years: the registration system of spinal surgery in tokohu university spine society. Tokohu J Exp Med. 2016; 238(2):153-63

4. Constandi S, Chopko S, Mekhail M, Dews T, Mekhail N. Lumbar spinal stenosis: therapeutic options review. Pain Pract. 2015; 15(1):68-81.

5. Weinstein JN, Tosteson TD, Lurie JD, Tosteson A, Blood E, Herkowitz H, Cammisa $F$, et al. Surgical versus non-operative treatment for lumbar spinal stenosis four year results of the spine patient outcomes research trial. Spine. 2010; 35(14):1329-38.

6. Burnett MG, Stein SC, Bartels RH. Cost-effectiveness of current treatment strategies for lumbar spinal stenosis: nonsurgical care, laminectomy and X-STOP. J Neurosurg Spine. 2010;13(1):39-46.

7. Usman M, Ali M, Khanzada K, Ishaq M, Naeem-ul-Haq, Aman R, et al. Unilateral approach for bilateral decompression of lumbar spinal stenosis: a minimal invasive surgery. J Coll Physicians Surg Pak. 2013; 23(12):852-6.

8. Lin CW, Haas M, Maher $\mathrm{Cg}$, Machado LA, Van Tulder MW. Cost effectiveness of general practice for low back pain: a systemic review. Eur Spine J. 2011; 20(7):1012-23.

9. Khan MB, Bashir MU, Kumar R, Enam $\mathrm{SA}$. Enduring improvement in Oswestry disability index outcomes following lumbar microscopic interlaminar decompression: an appraisal of prospectively collected patient outcomes. J Craniovertebr Junction Spine. 2015; 6(4): 195-9.

10. Hussain M, Nasir S, Moed A, Murtaza G. Variation in practice patterns among neurosurgeons and orthopedic surgeons in the management of spinal disorders. Asian Spine J. 2011; 5(4):20812.

11. Kasukawa Y, Miyakoshi N, Kobayashi T, Kikuchi K, Ebata K, Ishikawa N, Suzuki T, Sasaki H, Hatakeyama Y, Hongo M, Ishikawa Y. Limaprost or pregabalin: preoperative and postoperative medication for pain due to lumbar spinal stenosis. Pain Pract. 2018;18(5):625-30.

12. De Villiers PD, Booysen EL. Fibrous spinal stenosis. A report on 850 myelograms with water soluble contrast medium. Clin Orthop Relat Res. 1976; 140-4.

13. Deer T, Sayed D, Michels J, Josephson Y, Li S, Calodney AK. A review of lumbar spinal stenosis with intermittent neuro- genic claudication: disease and diagnosis. Pain Med. 2019; 20(2): S32-44.

14. Fanuele JC, Birkmeyer NJ, Abdu WA, Tosteson TD, Weinstein JN. The impact of spinal stenosis on the health status of the patients: have we underestimated the effect? Spine. 2000; 25:1509-14.

15. Wiesel SW, Tsourmas N, Feffer HL, Citrin CM, Patronas N. A study of computer-assisted tomography. I. The incidence of positive CAT scans in an asymptomatic group of patients. Spine. 1984; 9:549-551.

16. Adachi S, Nakano A, Kin A, Baba I, et al. The tibial nerve compression test for the diagnosis of lumbar spinal canal stenosis- a simple and reliable physical examination for use by primary care physicians. Acta Orthop Traumatol Turc. 2017; (16)30143-2.

17. Machado GC, Ferreira PH, Yoo Rl, Harris, et al. Surgical options for lumbar spinal stenosis. Cochrane Database Syst Rev. 2016; 11:12421.

18. Cheung JP, Kao PY, Sham P, Cheah KS, Chan D, Cheung KM, Samartzis D. Etiology of developmental spinal stenosis: A genome-wide association study. J Orth Res. 2018; 36(4):1262-8.

19. Shah S, Dalvie S, Rai R. Congenital malformed posterior arch of atlas with fusion defect: a case of developmental canal stenosis causing cervical myelopathy. J Spine Surg. 2017; 3(3):489497.

20. Verbiest $H$. The significance and principles of computerized axial tomography in idiopathic developmental stenosis of the bonylumbar vertebral canal. Spine.1979; 4:369-378.

21. Ullrich CG, Binet EF, Sanecki MG, Kieffer SA. Quantitative assessment of the lumbar spinal canal by computed tomography. Radiology. 1980; 134:137143.

22. Lee BC, Kazam E, Newman AD. Computed tomography of the spine and spinal cord. Radiology. 1978; 128:95-102. 
23. Schönström N, Willén J. Imaging lumbar spinal stenosis. Radiologic Clinics. 2001; 39(1):31-53.
24. Jarvik JJ, Hollingworth W, Heagerty $P$, Haynor DR, Deyo RA. The Longitudinal Assessment of Imaging and Disability of the Back (LAIDBack) Study: baseline data. Spine. 2001; 26:1158-1166.

\section{Author's Contribution}

ASP designed the study and formulated its methodology. AK designed the study and wrote the manuscript. SH analyzed the data and helped in writing the manuscript. FJ helped in data collection and write up of the manuscript. LR reviewed the literature and interpreted the results. Authors agree to be accountable for all aspects of the work in ensuring that questions related to the accuracy or integrity of any part of the work are appropriately investigated and resolved.

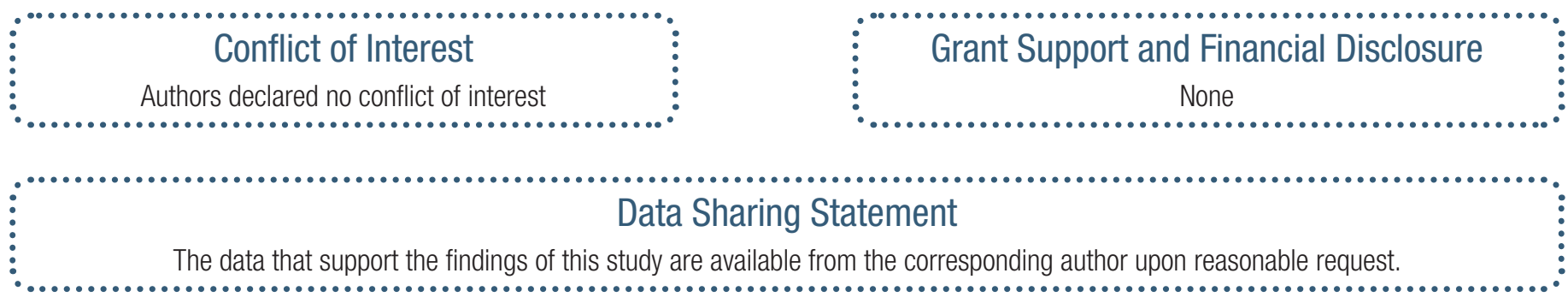

